\title{
Correction to: Intracranial foreign material granuloma after neurosurgical procedures
}

\author{
Shadi Al-Afif ${ }^{1}$ - Joachim K. Krauss ${ }^{1}$
}

Published online: 13 December 2018

(C) Springer-Verlag GmbH Austria, part of Springer Nature 2018

\section{Correction to: Acta Neurochirurgica}

https://doi.org/10.1007/s00701-018-3751-1

The title of the original article was incorrect in the published paper and is now corrected in this article. The word "martial" should be "material".

The original article has been corrected.

The online version of the original article can be found at https://doi.org/ 10.1007/s00701-018-3751-1

\footnotetext{
Shadi Al-Afif

al-afif.shadi@mh-hannover.de

1 Department of Neurosurgery, Hannover Medical School,

Carl-Neuberg Str. 1, 30625 Hanover, Germany
} 